\title{
Um método de ensaio para determinação da concentração de óleo em amostras de águas contaminadas com óleos e graxas
}

\author{
A test method for determining the oil concentration \\ in water samples contaminated with oil and grease
}

\begin{abstract}
Roberto Gonçalves de Carvalho** (1), Nadiane Smaha Kruk' ${ }^{\circledR}$, Elizabete Yoshie Kawachi' ${ }^{1}$, Paulo Ivo Braga de Queiroz' ${ }^{1}$
\end{abstract}

口-

\begin{abstract}
RESUMO
A concentração de óleos e graxas em amostras de águas contaminadas com resíduos oleosos pode ser determinada pelos procedimentos estabelecidos no Standard Methods for the Examination of Water and Wastewater. No entanto, sua aplicação nem sempre resulta em valores adequados ou níveis de precisão satisfatórios para atendimento de padrões normativos. Nesse sentido, este artigo apresenta uma proposta de ensaio para determinação da concentração de óleos minerais em águas provenientes de áreas pavimentadas, sujeitas ao derramamento de óleos e graxas. Tal método tem por base o método de partição gravimétrica (5520 B), estabelecido pelo Standard Methods. No novo procedimento, a etapa de separação entre o solvente de extração contendo os resíduos e o restante da fase aquosa foi substituída pela evaporação de toda a água da amostra, em estufa a $85^{\circ} \mathrm{C}$. Para avaliar a eficiência do método, foram preparadas amostras com concentrações conhecidas de óleo de 200, 100, 50, 25 e 15 mg.L-1 em água destilada e realizados ensaios de laboratório para determinação do teor de óleo, conforme tal procedimento. Os valores obtidos para as concentrações de óleo são bastante satisfatórios, apresentando comportamento linear em relação às concentrações de referência. Esse fato evidencia a confiabilidade do método proposto e sua aplicabilidade na determinação da concentração de óleos em amostras de águas contaminadas provenientes do escoamento superficial em pavimentos.
\end{abstract}

Palavras-chave: método de ensaio; concentração de óleo; escoamento superficial; pavimentos.

\begin{abstract}
Oil and grease concentration in water samples contaminated by oily residues can be determined by the procedures established in the Standard Methods for the Examination of Water and Wastewater. However, its application does not always result in adequate values or satisfactory accuracy levels in order to meet regulatory standards. In this sense, this paper presents a test-method proposal for determining mineral oil concentration in water samples from runoff of paved areas subject to oil and grease spillages. This method is based on the partitiongravimetric method (5520 B) established by the Standard Methods. In the new procedure, the separation between the extraction solvent containing residues and the aqueous phase remainder was replaced by the whole water sample evaporation in an oven at $85^{\circ} \mathrm{C}$. In order to assess the proposed method's efficiency, samples were prepared with known oil

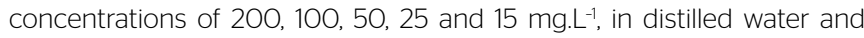
laboratory tests were performed to determine the oil content, according to the new procedure. The values obtained for the oil concentrations through the proposed procedure are quite satisfactory, presenting linear behavior in relation to the reference concentrations. This fact evidences the reliability of the new method and its applicability in determining the oil concentration in contaminated water samples from runoff in pavement surfaces.
\end{abstract}

Keywords: test method; oil concentration; runoff; pavements.

\section{INTRODUÇÃO}

A concentração de óleos e graxas presentes em águas contaminadas é recomendavelmente determinada pelos procedimentos de ensaio estabelecidos pelo Standard Methods for the Examination of Water and Wastewater, publicado pela American Public Health Association
(APHA), pela American Water Works Association (AWWA) e pela Water Environment Federation (WEF) (2012). Nessa importante referência, existem quatro métodos aplicáveis a amostras líquidas: o método de partição gravimétrica (5520 B), o método de partição infravermelho (5520 C), o método de Soxhlet (5520 D) e o método de partição

1instituto Tecnológico de Aeronáutica - São José dos Campos (SP), Brasil.

*Autor correspondente: carvargc@yahoo.com.br

Recebido: 11/12/2013 - Aceito: 26/O4/2018 - Reg. ABES: 127950 
gravimétrica com fase sólida $(5520 \mathrm{G})$. O método de partição infravermelho foi projetado para amostras que possam conter hidrocarbonetos voláteis que, nesse caso, seriam perdidos nas operações de remoção de solvente pelo procedimento gravimétrico. O método de Soxhlet é o mais adequado quando estão presentes frações de petróleo relativamente polares de elevada massa molecular ou quando os níveis de graxas não voláteis superam o limite de solubilidade do solvente. Para baixos teores de óleos e graxas ( $\left.<10 \mathrm{mg} . \mathrm{L}^{-1}\right)$, deve-se escolher o método de partição infravermelho, uma vez que o método de partição gravimétrica não fornece a precisão necessária. Existem ainda os métodos 5520 E, que é uma modificação do método de Soxhlet, cuja aplicação se faz adequada quando há presença de lodo ou elevada quantidade de materiais sólidos em suspensão; e $5520 \mathrm{~F}$, que pode ser usado em conjunto com os métodos 5520 B, 5520 C, 5520 D e 5520 G para obtenção somente de hidrocarbonetos, ao invés do total de óleos e graxas. Para a aplicação desse último método, é necessário o uso de sílica-gel para promover a separação de hidrocarbonetos do petróleo do total de óleos e graxas, presentes nas amostras contaminadas (APHA; AWWA; WEF, 2012).

As amostras a serem analisadas deverão ser coletadas em frascos que contenham boca larga, os quais deverão ser previamente lavados com detergente e água e posteriormente banhados com solventes que promovam a remoção de qualquer resíduo remanescente no frasco. Em geral, deverão ser coletadas na quantidade aproximada de $1 \mathrm{~L}$ por amostra, as quais não poderão ser divididas em outras amostras de menor volume. No caso de as análises serem realizadas após duas horas da coleta, as amostras deverão ser acidificadas para $\mathrm{pH} \leq 2$, por meio da adição de solução a 1:1 em volume de $\mathrm{HCl}$ ou de $\mathrm{H}_{2} \mathrm{SO}_{4}$ e estocadas à temperatura em torno de $8^{\circ} \mathrm{C}$ (APHA/AWWA/WEF, 2012).

A aplicação do APHA/AWWA/WEF (2012) para análise da quantidade de óleos e graxas em águas de abastecimento ou águas residuais restringe-se à determinação de gorduras biológicas e de hidrocarbonetos minerais. Sua aplicação também é adequada à maioria dos efluentes industriais ou efluentes tratados que contenham esses materiais.

As águas provenientes do escoamento superficial em áreas pavimentadas de rodovias e aeroportos contêm elevadas concentrações de óleos e graxas. O tráfego de veículos em vias de circulação urbana, assim como a movimentação de aeronaves em áreas aeroportuárias, são atividades de grande potencial para a ocorrência de derramamentos de hidrocarbonetos sobre os pavimentos, aumentando o risco de contaminação do meio ambiente (HELMREICH et al., 2010; CARRA; CONCEIÇÃO; TEIXEIRA, 2012; CARVALHO; KRUK, 2014; CARVALHO, 2014).

Em razão do crescente aumento nas operações de aeronaves em aeroportos, ocorrências de vazamentos e derramamentos de hidrocarbonetos derivados do petróleo têm se tornado eventos constantes, principalmente em áreas de abastecimento e manobras de aeronaves como hangares, pátios de estacionamento de aeronaves e pistas de pouso e decolagem (AZEVEDO, 2007; BARRIZON, 2012; SPIGLIATTI, 2012;
AMORIM \& AGUIAR, 2013). As movimentações de aeronaves, veículos e equipamentos de apoio ao solo em áreas aeroportuárias têm sido os principais agentes responsáveis por despejos ou derramamentos acidentais de óleos e graxas em pavimentos. As precipitações que produzem escoamento superficial (runoff) constituem no principal meio de dispersão dos óleos e das graxas acumulados nas superfícies dos pavimentos, levando à contaminação do solo e de cursos d'água existentes no entorno dos aeroportos (CARVALHO; KRUK, 2013).

Segundo Sulej, Polkowska e Namiesnik (2011), as águas escoadas provenientes de precipitações em aeroportos contêm elevadas concentrações de poluentes, como os hidrocarbonetos policíclicos aromáticos (HPAs), que são substâncias altamente tóxicas e potencialmente carcinogênicas. Essa poluição está atribuída ao desempenho de atividades antrópicas relacionadas às operações de aeronaves, como manutenção, reabastecimento, carga e descarga, bem como trânsito de veículos e equipamentos de apoio ao solo. Estudos conduzidos por Ray et al. (2008) revelaram a existência de elevadas concentrações de HPAs nos solos do entorno do Aeroporto Internacional de Nova Délhi, Índia. A exaustão de turbinas de aeronaves, que possui elevadas concentrações de gases poluentes resultantes da queima de hidrocarbonetos minerais, bem como os derramamentos acidentais de óleos lubrificantes e combustíveis derivados do petróleo sobre os pavimentos, são apontados como as principais causas para a contaminação do solo com HPAs (WATTS, 1997; ZHU et al., 2011; SULEJ; POLKOWSKA; NAMIESNIK, 2012).

Com o objetivo de avaliar a qualidade das águas pluviais provenientes de pátios e pistas de aeroportos, Carvalho (2014) realizou ensaios de laboratório em amostras de águas de chuva coletadas em superfícies de pavimentos aeroportuários contaminados com óleos minerais provenientes de aeronaves. Como a concentração máxima para lançamento de efluentes contaminados com óleos e graxas de origem mineral, provenientes de qualquer fonte poluidora, é estabelecida em 20 mg. $\mathrm{L}^{-1}$, por meio da Resolução do Conselho Nacional do Meio Ambiente (CONAMA) no 357 (BRASIL, 2005), complementada e alterada pela Resolução CONAMA no 430 (BRASIL, 2011), foi selecionado o método de partição gravimétrica (5520 B) do APHA/AWWA/WEF (2012), por ser o mais adequado à faixa de valores de concentrações de óleo a serem determinadas. Para avaliar a aplicação desse método, foi realizada uma simulação de ensaio utilizando uma amostra preparada em laboratório contendo uma quantidade conhecida de óleo de origem mineral, utilizado em motores de aeronaves. A aplicação do método $5520 \mathrm{~B}$ mostrou-se inadequada para a determinação da concentração de óleo da amostra de referência. Observou-se, nesse caso, a formação de uma emulsão de difícil separação de fases pelo procedimento gravimétrico. Esse fato motivou a pesquisa de novos procedimentos para a determinação da concentração de óleo das amostras.

Dessa forma, foi estabelecido um novo procedimento de ensaio, tendo por base o método $5520 \mathrm{~B}$, em que a etapa de separação entre o 
solvente de extração e o restante da fase aquosa, realizada com auxílio de funil de separação, foi substituída pela evaporação de toda a água da amostra em estufa a $85^{\circ} \mathrm{C}$. Para avaliar o procedimento proposto, foram realizadas simulações em amostras com concentrações conhecidas de óleo, preparadas em laboratório.

Este trabalho teve como objetivo apresentar o novo procedimento para determinação da concentração de óleo em amostras de águas provenientes de precipitações atmosféricas coletadas em superfícies de pavimentos contaminados com óleos e graxas, bem como avaliar o erro obtido na determinação da concentração de óleo em amostras com concentrações conhecidas.

Para que o procedimento tenha êxito, é necessário que não haja perda de óleo por evaporação durante a fase de secagem em estufa. Os óleos encontrados em pavimentos aeroportuários são de origem mineral e empregados em sistemas hidráulicos e motores de aeronaves e de veículos de apoio em solo. Esses óleos são fracionados para permitir a operação em faixas elevadas de temperatura e dificilmente contêm frações voláteis a temperaturas abaixo de $100^{\circ} \mathrm{C}$. Assim, o presente método pode ter aplicação em setores como aeroportos, refinarias, postos de combustíveis, áreas de estocagem, portos, rodovias, vias urbanas e estacionamento de veículos, bem como outras áreas sujeitas a derramamentos de óleos minerais.

\section{MATERIAIS E MÉTODOS}

Conforme já mencionado, o método de ensaio proposto neste trabalho segue os mesmos procedimentos estabelecidos no método $5520 \mathrm{~B}$ (APHA/AWWA/WEF, 2012). Do método original, preserva-se a mistura padrão utilizada como solvente de extração, mas suprime-se a etapa de separação entre o solvente e a fase líquida da amostra. Esse último procedimento é substituído pela evaporação de toda a água da amostra em uma estufa a $85^{\circ} \mathrm{C}$, previamente à etapa de adição do solvente de extração.

\section{Método de partição gravimétrica (5520 B)}

Conforme estabelecido no APHA/AWWA/WEF (2012), o método de partição gravimétrica utiliza uma mistura padrão de hexadecano/ácido esteárico a 1:1 em massa, na concentração de $2 \mathrm{mg} \cdot \mathrm{mL}^{-1}$ para cada substância em acetona, usada como solvente de extração. Conforme o procedimento descrito nesse método, primeiramente, deve-se marcar, no frasco de armazenagem da amostra, o nível do menisco inferior da interface líquido/ar para posterior determinação do seu volume. Em seguida, coloca-se a amostra em um funil de separação e adiciona-se $30 \mathrm{~mL}$ da mistura padrão. Mistura-se por 2 minutos e espera-se até que as fases se separem. Após a separação das fases, drena-se a fase aquosa para o frasco original de armazenagem da amostra, e a fase contendo a mistura padrão, ou seja, o solvente de extração juntamente com o óleo extraído, para um balão de fundo chato, passando-a por meio de um funil adaptado com papel filtro e $10 \mathrm{~g}$ de sulfato de sódio. Repete-se por mais duas vezes o procedimento de extração do óleo da amostra, adicionando $30 \mathrm{~mL}$ da mistura padrão ao funil de separação contendo a amostra, misturando por 2 minutos, aguardando a separação e posterior drenagem das fases. Ao final, adiciona-se mais $10 \mathrm{~mL}$ de solvente de extração ao balão de fundo chato por meio do funil contendo o papel filtro. O volume total do solvente de extração que foi adicionado ao balão de fundo chato deverá ser de aproximadamente $100 \mathrm{~mL}$. Após esse procedimento, deve-se realizar a destilação do solvente de extração contido no balão de fundo chato por meio da utilização de uma aparelhagem para destilação e recuperação de solventes e auxílio de câmara de vácuo, conforme ilustrado na Figura 1. Concluída a destilação de todo o solvente, restará no balão de fundo chato o óleo contido na amostra e os resíduos conhecidos do solvente de extração. Por meio da diferença de massa entre o balão de fundo chato vazio no início do ensaio e após a destilação do solvente, pode-se calcular a massa de óleo contido na amostra. Para se determinar o volume inicial da amostra, deve-se encher o frasco de armazenamento da amostra com água até a posição do menisco inferior da interface líquido/ar, anotada no início do ensaio, e com auxílio de uma proveta graduada, determina-se o seu volume. A concentração de óleo pode ser determinada por meio da relação entre a massa de óleo existente na amostra, em mg, e o volume, calculado em L.

\section{Método de ensaio proposto}

O propósito do presente trabalho foi apresentar um método inédito de ensaio para determinação da concentração de óleo em amostras de águas contaminadas com resíduos oleosos provenientes do escoamento superficial sobre superfícies pavimentadas. Portanto, com o objetivo de garantir a reprodução completa dos procedimentos, justifica-se a descrição, em detalhes, da aparelhagem e dos reagentes utilizados, bem como do procedimento de ensaio estabelecido para o método. A descrição apresentada adiante segue os moldes de descrição e o nível de detalhamento constantes no APHA/AWWA/WEF (2012).

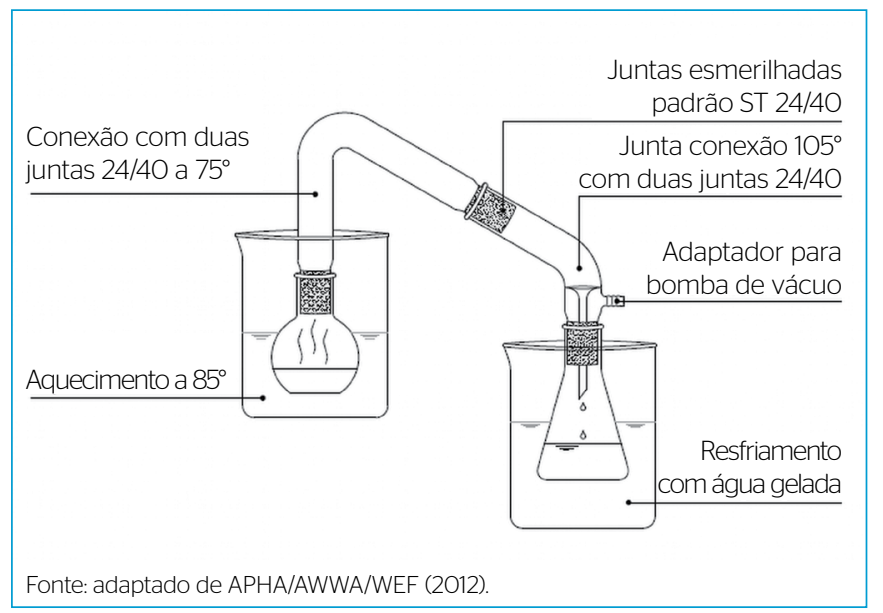

Figura 1 - Aparato para destilação e recuperação do solvente de extração. 


\section{Aparelhagem necessária}

Para o procedimento de ensaio foi estabelecida a seguinte aparelhagem:

- Balão volumétrico de $500 \mathrm{~mL}$;

- Balão volumétrico de $100 \mathrm{~mL}$;

- Pipeta graduada de $25 \mathrm{~mL}$;

- Funil para líquido em vidro;

- Frasco de vidro com boca larga e tampa de $1.000 \mathrm{~mL}$;

- Balão fundo chato $125 \mathrm{~mL}$ com junta esmerilhada 24/40;

- Erlenmeyer $125 \mathrm{~mL}$ com junta esmerilhada 24/40;

- Conexão com duas juntas $24 / 40$ a $75^{\circ}$;

- Junta conexão $105^{\circ}$ com duas juntas 24/40 com saída para vácuo;

- Papel filtro, $11 \mathrm{~cm}$ de diâmetro;

- Becker $500 \mathrm{~mL}$;

- Lente de vidro;

- Aquecedor;

- Aparato para resfriamento com água gelada;

- Câmara de vácuo;

- Balança com precisão de 0,001 g;

- Estufa com aquecimento $85^{\circ} \mathrm{C}$ mínimo;

\section{Substâncias e reagentes utilizados}

- Ácido clorídrico, com grau de pureza entre 36,5 e 38,0\%, na proporção 1:1 - mistura de iguais volumes de ácido e água;

- Acetona, resíduo menor que $1 \mathrm{mg} . \mathrm{L}^{-1}$;

- Hexadecano com mínimo de 98\% de pureza;

- Ácido esteárico com mínimo de 98\% de pureza;

- Sulfato de sódio, $\mathrm{Na}_{2} \mathrm{SO}_{4}$, cristal anidro. Seco a $200-250^{\circ} \mathrm{C}$ por $24 \mathrm{~h}$.

O ácido clorídrico é utilizado para correção do $\mathrm{pH}$ das amostras, conforme estabelecido no APHA/AWWA/WEF (2012) e no Guia Nacional de Coleta e Preservação de Amostras, como procedimento para preservação e armazenagem de amostras (CETESB, 2011). A acetona, composto orgânico com fórmula química $\mathrm{CH}_{3}(\mathrm{CO}) \mathrm{CH}_{3}$, é bastante utilizado como solvente para extração de óleos e gorduras. O hexadecano é um composto orgânico de origem mineral, de fórmula $\mathrm{CH}_{3}\left(\mathrm{CH}_{2}\right)_{14} \mathrm{CH}_{3}$ e solúvel em acetona. Por ser uma substância apolar, possui boa afinidade com hidrocarbonetos derivados do petróleo, contribuindo para maior eficiência na extração de componentes oleosos de origem mineral presentes na água. $\mathrm{O}$ ácido esteárico é um ácido graxo saturado com 18 carbonos, de fórmula química $\mathrm{CH}_{3}\left(\mathrm{CH}_{2}\right)_{16} \mathrm{COOH}$, obtido do fracionamento de ácidos graxos por meio da hidrólise do sebo de origem animal. Apresenta-se à temperatura ambiente na forma de pó ou grânulos de cor branca a levemente amarelada e possui leve odor característico. É bem utilizado como agente de consistência, é biodegradável, não é inflamável, tóxico ou poluente. Por ser uma substância polar, possui boa afinidade com óleos e gorduras de origem animal ou vegetal. O sulfato de sódio como cristal anidro é utilizado na secagem de óleos. Durante a filtragem do solvente de extração, é posto sulfato de sódio no papel filtro, que provoca a sua hidratação retirando qualquer remanescente de água ou umidade contida na solução com o óleo e a acetona. O sulfato de sódio não é solúvel em acetona.

\section{Preparo da mistura padrão (solvente de extração)}

Conforme estabelecido no método 5520 B do APHA/AWWA/WEF (2012), a mistura padrão é uma solução de acetona contendo $4 \mathrm{mg}$. $\mathrm{mL}^{-1}$ de hexadecano e ácido esteárico em igual proporção. A mistura poderá ser preparada em laboratório ou ser adquirida pronta, sendo recomendado o seu preparo em laboratório no mesmo dia da realização dos ensaios, em razão da alta volatilidade do solvente acetona.

Em laboratório, deve-se preparar a mistura por meio do seguinte procedimento: colocar $1.000( \pm 2) \mathrm{mg}$ de ácido esteárico e $1.000( \pm 2)$ mg de hexadecano em um balão volumétrico de $500 \mathrm{~mL}$ e completar com acetona até a sua marca. Para a completa dissolução do ácido esteárico, é necessário um leve aquecimento (cerca de $40^{\circ} \mathrm{C}$ ) da solução. Para confirmar a concentração de óleo da solução, remover 10 $( \pm 0,1) \mathrm{mL}$ da mistura padrão com uma pipeta e destilar o solvente, por meio do aparato para destilação e recuperação do solvente apresentado na Figura 1. A massa final do resíduo deve ser de 40 ( \pm 1$)$ mg. Caso contrário, deve ser preparada uma nova solução (APHA; AWWA; WEF, 2012).

\section{Procedimento de ensaio}

As amostras a serem analisadas deverão ser armazenadas em frascos de vidro contendo boca larga e volume de $1 \mathrm{~L}$, previamente lavados e isentos de quaisquer resíduos. Caso o procedimento de ensaio não se inicie em até 2 horas após a coleta, as amostras deverão ser armazenadas em temperatura em torno de $8^{\circ} \mathrm{C}$, após ajuste de $\mathrm{pH}$ para valores inferiores a 2, por meio da adição de ácido clorídrico.

O procedimento de ensaio tem início com a introdução do frasco contendo a amostra em uma estufa ajustada para a temperatura de $85^{\circ} \mathrm{C}$, para evaporação da fase aquosa, por cerca de 4 dias (96 horas), ou até que toda a água seja evaporada. Após a evaporação da fase aquosa, o frasco deve ser removido e mantido em repouso fora da estufa por cerca de 20 minutos ou até ser atingida a temperatura ambiente.

A extração do óleo contido no interior do frasco de cada amostra deve ser realizada logo após o frasco atingir o equilíbrio com a temperatura ambiente, conforme o seguinte procedimento: primeiramente, adiciona-se $100 \mathrm{~mL}$ da mistura padrão, ou solvente de extração, ao interior do frasco contendo o resíduo de óleo que restou após a evaporação da fase aquosa da amostra na estufa. Com o frasco tampado, agita-se suavemente o conteúdo por cerca de 1 minuto e filtra-se a solução do solvente de extração contento os resíduos diretamente para um balão de fundo chato de $125 \mathrm{~mL}$ (previamente pesado), utilizando um funil analítico com papel filtro contendo $10 \mathrm{~g}$ de sulfato de sódio. 
Em seguida, lava-se o balão em que a solução padrão estava armazenada com cerca de $10 \mathrm{~mL}$ de acetona, agitando-se o conteúdo por cerca de 30 segundos, e posteriormente o frasco de armazenagem da amostra, com os mesmos $10 \mathrm{~mL}$ de acetona; filtra-se o resíduo e coleta-se o filtrado no balão de fundo chato por meio do mesmo funil contendo o papel filtro e os $10 \mathrm{~g}$ de sulfato de sódio usados anteriormente. Novamente, repete-se esse último procedimento com mais $10 \mathrm{~mL}$ de acetona e despeja-se no funil. Com isso, busca-se extrair ao máximo a solução padrão com o óleo da amostra, retida no frasco, no balão volumétrico, no papel filtro e no sulfato de sódio. O balão de fundo chato, por meio da sua junta esmerilhada, deve ser adaptado ao aparato de destilação do solvente, conforme ilustrado na Figura 1. Durante a destilação, pode-se observar visualmente a evaporação do solvente de extração no balão de fundo chato, bem como sua condensação e recolhimento no Erlenmeyer. Quando não for mais visível o fluxo do solvente destilado, deve-se conectar o sistema ao dispositivo de vácuo por cerca de 2 minutos ou até que todo o solvente seja removido do balão de fundo chato.

$\mathrm{Na}$ sequência, remove-se o balão de fundo chato do aparato de destilação e espera-se por cerca de 10 minutos para o resfriamento e o equilíbrio das condições ambientes para posterior pesagem. Após a pesagem do balão de fundo chato, subtrai-se a massa do balão vazio, medido antes do ensaio, e a massa de $400 \mathrm{mg}$ relativos aos sólidos (200 mg relativos ao hexadecano e $200 \mathrm{mg}$, ao ácido esteárico), ambos contidos nos $100 \mathrm{~mL}$ de solvente de extração utilizados no ensaio, para extração do óleo contido na amostra.

A concentração de óleo na amostra é determinada por meio da razão entre a massa do óleo obtido e o volume da fase aquosa. Este é medido por meio da quantidade de água necessária para preencher o frasco de armazenagem da amostra até o nível do menisco inferior da interface líquido/ ar, anotado previamente à etapa de secagem da fase aquosa na estufa.

Obtém-se, portanto, a concentração de óleo na amostra a partir da Equação 1:

Concentração de óleo $\left(m g . L^{-1}\right)=\frac{M_{\text {olleo }}}{V_{\text {amostra }}}$

Em que:

$M_{\text {óleo }}=$ a massa de óleo, em mg, obtida da massa total do balão de fundo chato e resíduos subtraída da massa do balão de fundo chato vazio e de $400 \mathrm{mg}$ referentes ao hexadecano e ácido esteárico;

$V_{\text {amostra }}=$ o volume inicial da amostra, em $\mathrm{L}$.

\section{Avaliação do novo método}

Para avaliar o método de ensaio proposto, foram preparadas 15 amostras em frascos de vidro de $1 \mathrm{~L}$, limitando-se a uma faixa de concentrações de trabalho entre 200 e $15 \mathrm{mg} . \mathrm{L}^{-1}$, com as concentrações de referência de 200, 100, 50, 25 e $15( \pm 1)$ mg. $\mathrm{L}^{-1}$ de óleo mineral em solução de água destilada, sendo três amostras para cada concentração. $\mathrm{O}$ pH das amostras foi ajustado para valor menor ou igual a 2 com a adição média de $2 \mathrm{~mL}$ de solução de ácido clorídrico diluído em água a 50\% em volume. Apesar de os procedimentos de preservação de amostras estabelecidos no APHA, AWWA e WEF (2012) permitirem o ajuste do $\mathrm{pH}$ por meio da adição de ácido sulfúrico, para o procedimento proposto foi utilizado o ácido clorídrico por apresentar ponto de ebulição em torno de $109^{\circ} \mathrm{C}$ e ser facilmente evaporado junto à água durante a fase de secagem na estufa. Após seu preparo, as amostras foram levadas à estufa a $85^{\circ} \mathrm{C}$ para evaporação da fase aquosa por cerca de 4 dias (96 horas), ou até que toda a fase líquida fosse evaporada.

Previamente à realização dos ensaios para a extração do óleo das amostras, foi feita a calibração da balança eletrônica da marca Marte, $\mathrm{n}^{\circ}$ série 253793, carga máxima de 200 g e precisão de 0,001 g, utilizada neste estudo, conforme o Certificado de Calibração MF-M 030/13, emitido pelo Laboratório de Metrologia Física do Instituto de Fomento e Coordenação Industrial (IFI), órgão do Departamento de Ciência e Tecnologia Aeroespacial (DCTA), localizado em São José dos Campos, São Paulo. Os outros equipamentos utilizados nesta pesquisa foram:

- Estufa da marca Blue M Electric, modelo PRO-SET II, $120 \mathrm{~V} / 1 \mathrm{PH} / 60 \mathrm{~Hz}$, para faixas de temperatura entre 38 e $260^{\circ} \mathrm{C}$;

- Bomba de vácuo da marca LC Ind., Com. E Manutenção Ltda., modelo no 101 e nº de série 188506.

Os ensaios foram conduzidos no Laboratório de Hidráulica do Departamento de Recursos Hídricos e Saneamento Ambiental da Divisão de Engenharia Civil do Instituto Tecnológico de Aeronáutica (ITA).

O óleo utilizado neste estudo foi o lubrificante Aeroshell Turbine Oil 560 MIL-PRF-23699F CLASS HTS, para uso em motores de aeronaves, obtido no Instituto de Pesquisas e Ensaios em Voo (IPEV), órgão do DCTA. O Aeroshell Turbine Oil 560 apresenta ponto de ebulição de $280^{\circ} \mathrm{C}$ e perda de massa de $2,4 \%$ quando exposto à temperatura de $204^{\circ} \mathrm{C}$ por 6,5 horas (SHELL, 2013).

Visando avaliar a perda de massa por volatilidade do óleo utilizado no estudo, foram preparadas três amostras contendo $100( \pm 1)$ mg de óleo em uma lente de vidro de relógio e levadas à estufa à temperatura de $85^{\circ} \mathrm{C}$ por um período de 48 horas. Após o tempo de permanência na estufa, as amostras foram pesadas para determinação da perda de massa do óleo.

\section{RESULTADOS E DISCUSSÃO}

Os resultados para a perda de massa das três amostras com $100( \pm 1) \mathrm{mg}$ do lubrificante Aeroshell Turbine Oil560 MIL-PRF-23699F CLASS HTS (SHELL, 2013), utilizado como referência, após a permanência por um período de 48 horas em estufa à temperatura de $85^{\circ} \mathrm{C}$ são apresentados na Tabela 1.

Considerando-se a diferença das massas da lente de vidro de relógio (MVR) com óleo, antes e após a permanência por 48 horas na estufa, 
observa-se que a perda de óleo máxima foi de $1( \pm 2) \mathrm{mg}$, estando esse valor associado, provavelmente, ao nível de precisão do instrumento de medida, que é de $\pm 1 \mathrm{mg}$, e não a uma perda real da massa de óleo. Portanto, considera-se que não há perda de óleo para o nível de temperatura do ensaio.

$\mathrm{Na}$ Tabela 2, são apresentados os resultados obtidos para a extração do óleo contido nas amostras de $1 \mathrm{~L}$ de água destilada, para as concentrações de referência de 200, 100, 50, 25 e 15 ( \pm 1) mg. $\mathrm{L}^{-1}$, utilizando $100 \mathrm{~mL}$ da solução padrão, que contêm $400( \pm 2) \mathrm{mg}$ de resíduos.

A terceira coluna da Tabela 2 (massa total de óleo e resíduos de referência) refere-se à quantidade teórica do óleo de referência, somada às massas das substâncias hexadecano e ácido esteárico existentes em $100 \mathrm{~mL}$ do solvente de extração. A quarta coluna da mesma tabela (massa do balão vazio) refere-se à massa do balão de fundo chato vazio medida no início do ensaio, enquanto a quinta coluna (massa do balão com óleo e resíduos) se refere à massa do balão medida ao final do procedimento de destilação e recuperação do solvente, para cada amostra. A sexta coluna (massa total de óleo e resíduos calculada) refere-se à quantidade total de óleo e resíduos resultante da diferença entre as massas do balão de fundo chato vazio, ou seja, antes da introdução do solvente de extração contendo o óleo e os resíduos, e após a destilação do solvente.

O erro relativo percentual máximo foi calculado por meio da relação entre a massa total de óleo e resíduos teórica, subtraída da massa total de óleo e resíduos calculada, pela massa total de óleo e resíduos teórica, multiplicada por $100 \%$, considerando os valores dos desvios máximos relativos à incerteza do instrumento de medição. Da análise da Tabela 2, observa-se que houve uma perda de massa, uma vez que as massas totais de óleo e resíduos calculadas por meio do procedimento de ensaio resultaram em valores menores que os teóricos, com percentuais de erro variando entre 0,7 e 2,2\%, resultando em um percentual de recuperação do solvente de extração entre 99,3 e 97,8\%. Esses valores estão acima do percentual de recuperação do solvente obtido no método de partição gravimétrica (5520 B), que prevê valores médios superiores a 93\%, ou seja, percentuais de perda de até 7\% (APHA; AWWA; WEF, 2012).

Com o objetivo de determinar a quantidade dessa perda relativa aos resíduos hexadecano e ácido esteárico, foi avaliado o mesmo procedimento em outras três amostras, contendo apenas $1 \mathrm{~L}$ de água destilada, sem presença de óleo. Os resultados mostraram uma recuperação dos

Tabela 1 - Perdas de massa para amostras de $100( \pm 1) \mathrm{mg}$ de óleo mineral após 48 horas em estufa à temperatura de $85^{\circ} \mathrm{C}$.

\begin{tabular}{c|c|c|c|c|c} 
Amostra & $\begin{array}{c}\text { MVR } \\
\text { vazia (mg) }\end{array}$ & $\begin{array}{c}\text { MVR com } \\
\text { óleo (mg) }\end{array}$ & $\begin{array}{c}\text { MVR com óleo } \\
\text { após 48h (mg) }\end{array}$ & $\begin{array}{c}\text { Massa de óleo } \\
\text { após 48h (mg) }\end{array}$ & $\begin{array}{c}\text { Perda } \\
\text { de massa (mg) }\end{array}$ \\
\hline 1 & $15.215 \pm 1$ & $15.315 \pm 1$ & $15.314 \pm 1$ & $99 \pm 2$ & $1 \pm 2$ \\
\hline 2 & $15.459 \pm 1$ & $15.559 \pm 1$ & $15.558 \pm 1$ & $99 \pm 2$ & $1 \pm 2$ \\
\hline 3 & $15.215 \pm 1$ & $15.315 \pm 1$ & $15.315 \pm 1$ & $100 \pm 2$ & $0 \pm 2$ \\
\hline
\end{tabular}

MVR: massa da lente de vidro de relógio.

Tabela 2 - Resultados dos ensaios de laboratório para as concentrações de referência de óleo de 200, 100, 50,25 e 15 ( $( \pm 1)$ mg.L느.

\begin{tabular}{|c|c|c|c|c|c|c|}
\hline Amostra & $\begin{array}{l}\text { Concentração de } \\
\text { referência } \\
\left(\mathrm{mg} \cdot \mathrm{L}^{-1}\right)\end{array}$ & $\begin{array}{l}\text { Massa total de óleo e } \\
\text { resíduos de referência } \\
(\mathrm{mg})\end{array}$ & $\begin{array}{c}\text { Massa do } \\
\text { balão vazio (mg) }\end{array}$ & $\begin{array}{l}\text { Massa do balão com } \\
\text { óleo e resíduos (mg) }\end{array}$ & $\begin{array}{l}\text { Massa total de óleo } \\
\text { e resíduos calculada } \\
\text { (mg) }\end{array}$ & $\begin{array}{l}\text { Erro relativo } \\
\text { (\%) }\end{array}$ \\
\hline 1 & $200 \pm 1$ & $600 \pm 2$ & $62.313 \pm 1$ & $62.907 \pm 1$ & $594 \pm 2$ & 1,3 \\
\hline 2 & $200 \pm 1$ & $600 \pm 2$ & $62.967 \pm 1$ & $63.559 \pm 1$ & $592 \pm 2$ & 1,7 \\
\hline 3 & $200 \pm 1$ & $600 \pm 2$ & $65.119 \pm 1$ & $65.712 \pm 1$ & $593 \pm 2$ & 1,5 \\
\hline 4 & $100 \pm 1$ & $500 \pm 2$ & $62.968 \pm 1$ & $63.466 \pm 1$ & $498 \pm 2$ & 0,8 \\
\hline 5 & $100 \pm 1$ & $500 \pm 2$ & $73.731 \pm 1$ & $74.222 \pm 1$ & $491 \pm 2$ & 2,2 \\
\hline 6 & $100 \pm 1$ & $500 \pm 2$ & $62.313 \pm 1$ & $62.806 \pm 1$ & $493 \pm 2$ & 1,8 \\
\hline 7 & $50 \pm 1$ & $450 \pm 2$ & $73.731 \pm 1$ & $74.177 \pm 1$ & $446 \pm 2$ & 1,3 \\
\hline 8 & $50 \pm 1$ & $450 \pm 2$ & $62.967 \pm 1$ & $63.411 \pm 1$ & $444 \pm 2$ & 1,8 \\
\hline 9 & $50 \pm 1$ & $450 \pm 2$ & $62.313 \pm 1$ & $62.762 \pm 1$ & $449 \pm 2$ & 0,7 \\
\hline 10 & $25 \pm 1$ & $425 \pm 2$ & $73.731 \pm 1$ & $74.152 \pm 1$ & $421 \pm 2$ & 1,4 \\
\hline 11 & $25 \pm 1$ & $425 \pm 2$ & $62.313 \pm 1$ & $62.732 \pm 1$ & $419 \pm 2$ & 1,9 \\
\hline 12 & $25 \pm 1$ & $425 \pm 2$ & $73.731 \pm 1$ & $74.153 \pm 1$ & $422 \pm 2$ & 1,2 \\
\hline 13 & $15 \pm 1$ & $415 \pm 2$ & $65.119 \pm 1$ & $65.529 \pm 1$ & $410 \pm 2$ & 1,7 \\
\hline 14 & $15 \pm 1$ & $415 \pm 2$ & $65.119 \pm 1$ & $65.532 \pm 1$ & $413 \pm 2$ & 1,0 \\
\hline 15 & $15 \pm 1$ & $415 \pm 2$ & $62.313 \pm 1$ & $62.725 \pm 1$ & $412 \pm 2$ & 1,2 \\
\hline
\end{tabular}


resíduos variando de $395( \pm 2)$ a $397( \pm 2) \mathrm{mg}$, conforme apresentado na Tabela 3, evidenciando, portanto, uma perda em razão dos resíduos do solvente de extração.

Conclui-se, portanto, que as amostras contaminadas com óleo apresentam perdas relativas, tanto ao óleo contido na amostra quanto aos resíduos do solvente de extração. Durante a fase de passagem do solvente pelo papel filtro contendo $10 \mathrm{~g}$ de sulfato de sódio, observou-se que parte do solvente permanecia nos poros do papel filtro, uma vez que este ficava encharcado com o solvente e, consequentemente, uma parte ficava retida no funil. A alta volatilidade da acetona fazia com que os resíduos dissolvidos no solvente permanecessem no papel filtro com sulfato de sódio após a sua evaporação.

A Tabela 4 apresenta uma síntese dos valores de concentração de óleo obtidos para as concentrações de referência de 200, 100, 50, 25 e $15 \mathrm{mg} . \mathrm{L}^{-1}$, agrupando-os em categorias de valores definidas como máximo, mediana, mínimo e média. Os valores das concentrações de óleo foram determinados descontando-se a massa total teórica de resíduos do solvente de extração, igual a $400 \mathrm{mg}$, dos valores de massa total de óleo e resíduos obtidos por meio do procedimento de ensaio. Apesar de ter sido evidenciado que parte das perdas é atribuída aos resíduos do solvente de extração, optou-se pela subtração da massa total dos resíduos, com a sugestão de se determinar uma estimativa da perda relativa aos resíduos em um estudo específico.

Como pode ser observado na Figura 2, há perda média de óleo de 7, 6, 3,7, 4,3 e 3,3 para as concentrações de 200, 100, 50, 25 e 15 mg.L-1 respectivamente, sendo que seus valores médios decrescem à medida que as concentrações de referência das amostras diminuem.

Conforme apresentado por Albano e Raya-Rodriguez (2009), para todo método quantitativo haverá uma faixa de concentrações da substância em análise na qual o método pode ser aplicado. Essa faixa terá como fatores limitantes os valores dos limites de detecção e de quantificação do método como limite inferior. No limite superior, os fatores limitantes dependerão do sistema de resposta do equipamento de medição, ou, no caso do procedimento em questão, do limite de solubilidade do óleo pelo solvente de extração. Dentro dessa faixa de trabalho, ou seja, dentro da faixa de concentrações que poderão ser avaliadas pelo procedimento em análise, haverá uma faixa na qual os valores resultantes de aplicação do método apresentarão relação linear com a substância em análise. A faixa linear é definida como a faixa de concentrações na qual a sensibilidade pode ser considerada constante e é, normalmente, expressa nas mesmas unidades do resultado obtido pelo método analítico.

A máxima extensão da faixa linear pode ser estabelecida durante a avaliação da faixa de trabalho, o que não constituiu no objetivo deste estudo. Uma faixa linear de trabalho de um método de ensaio é o intervalo entre os níveis inferior e superior de concentração da substância em análise, no qual se demonstra ser possível a sua determinação com a precisão, a exatidão e a linearidade exigidas sob as condições especificadas para o ensaio. Uma faixa de trabalho é considerada linear quando o resultado do fator $\mathrm{R}^{2}$ da regressão linear entre a concentração de referência da substância em análise e a resposta analítica resultante da aplicação do método de ensaio apresentar valor maior que 0,99 (ALBANO; RAYA-RODRIGUEZ, 2009).

Para avaliar a linearidade da faixa de concentrações avaliadas neste estudo, foi realizada a regressão linear entre os valores das concentrações

Tabela 4 - Valores máximos, medianos, mínimos e médias obtidas para as concentrações de referência de 200, 100, 50, 25 e 15 mg. $\mathrm{L}^{-1}$.

\begin{tabular}{l|c|c|c|c|c}
\multirow{2}{*}{$\begin{array}{l}\text { Valores } \\
\text { obtidos }\end{array}$} & \multicolumn{5}{|c}{ Concentração das amostras (mg.L-1) } \\
\cline { 2 - 6 } Máximo & 200 & 100 & 50 & 25 & 15 \\
\hline Mediana & 194 & 98 & 49 & 22 & 13 \\
\hline Mínimo & 193 & 93 & 46 & 21 & 12 \\
\hline Média & 192 & 91 & 44 & 19 & 10 \\
\hline
\end{tabular}

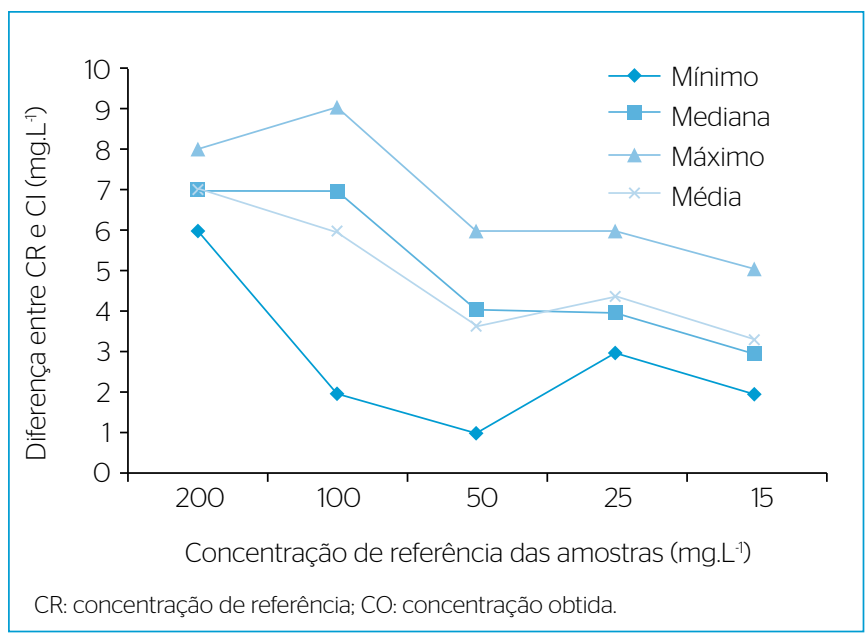

Figura 2 - Perdas máximas, medianas, mínimas e médias de óleo para as concentrações de referência.

Tabela 3 - Resultados dos ensaios de laboratório para amostras sem óleo.

\begin{tabular}{c|c|c|c|c}
$\begin{array}{c}\text { MT resíduos } \\
\text { teórica }(\mathrm{mg})\end{array}$ & $\begin{array}{c}\text { MB vazio } \\
(\mathrm{mg})\end{array}$ & $\begin{array}{c}\text { MB com } \\
\text { resíduos (mg) }\end{array}$ & $\begin{array}{c}\text { MT resíduos } \\
\text { calculada (mg) }\end{array}$ & $\begin{array}{c}\text { Erro relativo } \\
\text { (\%) }\end{array}$ \\
\hline 400 & $62.967 \pm 1$ & $63.362 \pm 1$ & $395 \pm 2$ & 1,8 \\
\hline 400 & $65.119 \pm 1$ & $65.516 \pm 1$ & $397 \pm 2$ & 1,3 \\
\hline 400 & $73.731 \pm 1$ & $74.128 \pm 1$ & $397 \pm 2$ & 1,3 \\
\hline
\end{tabular}

MT: massa total; MB: massa do balão. 
de referência, plotados no eixo $\mathrm{x}$, e os valores das concentrações de óleo resultantes da aplicação do método, plotados no eixo y, analisados em triplicata, conforme apresentado na Figura 3. O valor $\mathrm{R}^{2}$ obtido para uma aproximação linear foi superior a 0,99, evidenciando a linearidade do método para a faixa de trabalho estudada.

Com o objetivo de identificar a ocorrência de tendências ou possíveis erros sistemáticos, foi calculado os resíduos da regressão linear e plotado o gráfico de perfil dos resíduos, conforme apresentado na Figura 4. Da análise do gráfico do perfil dos resíduos, pode-se concluir que não houve concentrações dos valores localizadas, evidenciando a ocorrência de uma ordem aleatória da distribuição dos resíduos, que indicam a ausência de tendências e erros sistemáticos ao longo da faixa de concentrações de referência avaliadas.

Ressalta-se que os valores de concentração de óleo apresentados na Tabela 4 e na Figura 3 foram obtidos descontando-se da massa total de óleo e resíduos, que restaram no balão de fundo chato após o procedimento de destilação, a massa de $400 \mathrm{mg}$ relativa ao total de resíduos do solvente de

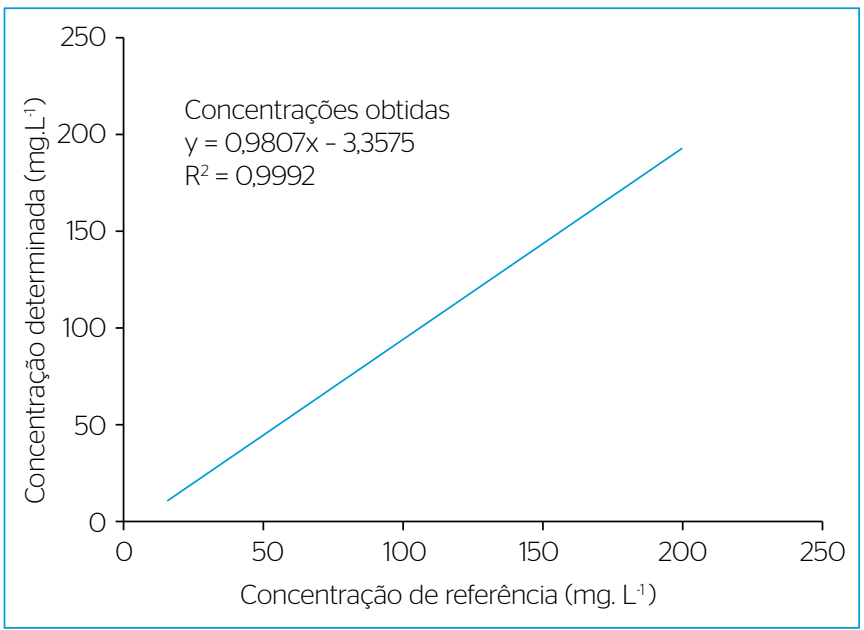

Figura 3 - Gráfico da linearidade que demonstra $\mathrm{R}^{2}$ superior a 0,99.

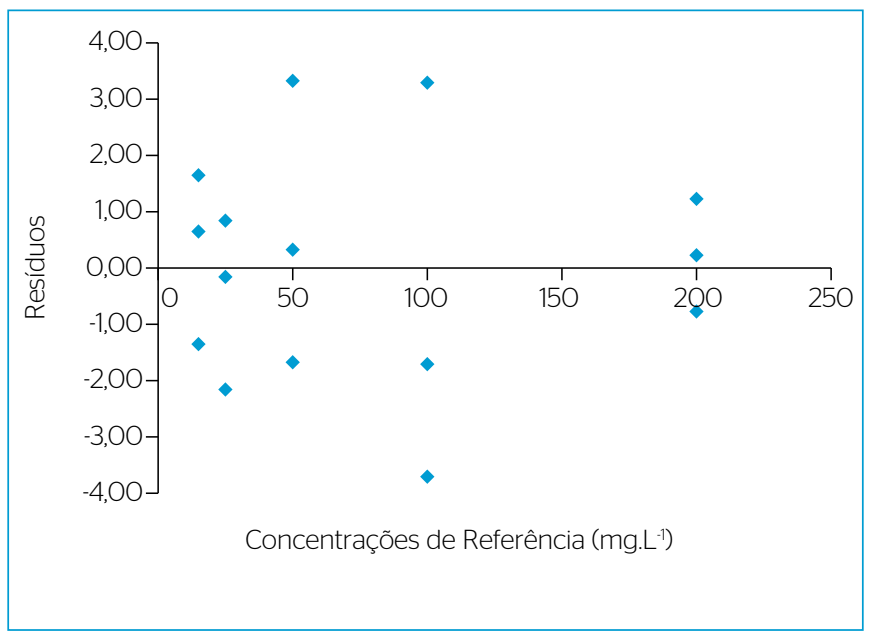

Figura 4 - Gráfico do perfil dos resíduos. extração, sem levar em consideração as perdas relativas aos resíduos de hexadecano e ácido esteárico contidas no solvente. Essa perda constitui-se de um erro sistemático, que foi corrigido com a regressão linear apresentada na Figura 3. Esse erro sistemático inclui um intercepto de 3,3575 mg, muito próximo à diferença entre os valores da primeira e da quarta colunas da Tabela 3, que se constitui da perda da massa de solvente de extração.

Dessa forma, para a faixa de trabalho com concentrações variando de $200 \mathrm{a} 15 \mathrm{mg} . \mathrm{L}^{-1}$, pode-se concluir que o método de ensaio proposto apresentou comportamento linear, uma vez que os resultados obtidos pela aplicação do método são diretamente proporcionais às concentrações de referência para as amostras estudadas. Ressalta-se, ainda, que os erros sistemáticos mencionados no parágrafo anterior são pouco significativos; mesmo sem a correção desses erros, o método proposto ainda possui acurácia superior à do método de partição gravimétrica 5520 B (APHA; AWWA; WEF, 2012).

\section{CONCLUSÕES}

A determinação da concentração de óleo em amostras líquidas, com base no método de evaporação da fase aquosa em estufa a $85^{\circ} \mathrm{C}$, proposto neste estudo, apresentou resultados satisfatórios quando aplicada a amostras contendo água destilada contaminada com óleo de origem mineral. Os percentuais de erro do método variaram entre 0,7 e 2,2\%, e o percentual mínimo de recuperação do solvente de extração foi de $97,8 \%$, estando acima do percentual de recuperação do solvente obtido no método de partição gravimétrica $(5520$ B) do Standard Methods (APHA; AWWA; WEF, 2012), que estabelece valores superiores a 93\% para recuperação do solvente, ou seja, percentuais de perda de até $7 \%$.

Os resultados mostraram a ocorrência de uma pequena perda de óleo e resíduos do solvente de extração, que aumenta à medida que aumenta a concentração de óleo na amostra. Essa perda foi atribuída, principalmente, à quantidade de solvente retida no meio poroso do papel filtro $\mathrm{e}$ sulfato de sódio contendo parte do óleo extraído juntamente com os resíduos de hexadecano e ácido esteárico existentes no solvente de extração.

Os resultados obtidos da aplicação do procedimento para um conjunto de 15 amostras de óleo analisadas apresentaram valores proporcionais quando comparados às concentrações de referência de cada amostra, dentro da faixa de trabalho de 200 a 15 mg. $\mathrm{L}^{-1}$, evidenciando a linearidade do método analítico quantitativo.

Como sugestão para pesquisas futuras, será de grande relevância o estudo de uma faixa de trabalho mais extensa, que tenha como limitantes inferior e superior os limites de quantificação/detecção do método e a capacidade de solubilidade de óleo em $100 \mathrm{~mL}$ de solvente de extração, respectivamente. Sugere-se ainda um estudo específico para determinar as perdas relativas ao resíduo de extração em amostras sem a presença de óleo, com o objetivo de se estabelecer uma estimativa para a perda de massa desse resíduo, para o volume de $100 \mathrm{~mL}$ de solvente de extração a ser utilizado no procedimento. 


\section{REFERÊNCIAS}

ALBANO, F.M.; RAYA-RODRIGUEZ, M.T. (2009) Validação e Garantia da Qualidade de Ensaios Laboratoriais - Guia Prático. Porto Alegre: Rede Metrológica RS.

AMERICAN PUBLIC HEALTH ASSOCIATION (APHA); AMERICAN WATER WORKS ASSOCIATION (AWWA); WATER ENVIRONMENT FEDERATION (WEF). (2012) Standard Methods for the Examination of Water and Wastewater. 22. ed. Washington, D.C:: APHA/AWWA/WEF.

AMORIM, B.; AGUIAR, P. (2013) Vazamento de óleo fechou pista do Santos Dumont até o meio da tarde. O Globo, Rio de Janeiro, 24 out. 2013. Disponível em: <http://oglobo.globo.com/rio/vazamentode-oleo-fechou-pista-principal-do-santos-dumont-ate-meio-datarde-10523662>. Acesso em: 26 out. 2013.

AZEVEDO, H.P.M. (2007) Descrição do Projeto do Sistema Separador de Água e Óleo do Aeroporto de Congonhas. $82 f$. Trabalho de Conclusão de Curso (Graduação) - Universidade Anhembi Morumbi, São Paulo.

BARRIZON, I. (2012) Vazamento de óleo deixa pista de aeroporto interditada. Gazeta Digital, Várzea Grande, 13 jun. 2012. Disponível em: <http://www2.gazetadigital.com.br/conteudo/show/secao/9/ og/1/materia/329994/t/vazamento-de-oleo-deixa-pista-deaeroporto-interditada>. Acesso em: 24 out. 2013.

BRASIL. (2005) Resolução CONAMA no 357, de 17 de março de 2005. Dispõe sobre a classificação dos corpos de água e diretrizes ambientais para o seu enquadramento, bem como estabelece as condições e padrões de lançamento de efluentes, e dá outras providências. Diário Oficial da República Federativa do Brasil, Brasília.

(2011) Resolução CONAMA no 430, de 13 de maio de 2011. Dispõe sobre as condições e padrões de lançamento de efluentes, complementa e altera a Resolução no 357, de 17 de março de 2005, do Conselho Nacional do Meio Ambiente - CONAMA. Diário Oficial da República Federativa do Brasil, Brasília.

CARRA, T.A.; CONCEIÇÃO, F.T;; TEIXEIRA, B.B. (2012) Avaliação de riscos ambientais no Aeroporto Internacional de Viracopos, Campinas (SP). Revista Brasileira de Geociências, v. 42, supl. 1, p. 5769. http://dx.doi.org/10.5327/Z0375-75362012000500006

CARVALHO, R.G. (2014) Proposta de Dimensionamento de Sistema de Separação Água/Óleo em Aeroportos. 152f. Dissertação (Mestrado em Infraestrutura Aeroportuária) - Instituto Tecnológico de Aeronáutica, São José dos Campos.
CARVALHO, R.G.; KRUK, N.S. (2O13) Critérios de dimensionamento para sistemas de separação água/óleo em aeroportos. In: SIMPÓSIO BRASILEIRO DE RECURSOS HÍDRICOS, 20., 2013, Bento Gonçalves. Anais... Bento Gonçalves.

CARVALHO, R.G.; KRUK, N.S. (2014) Dimensionamento de sistemas de separação água/óleo em aeroportos utilizando tanques de equalização. In: SIMPÓSIO IBERO-AMERICANO DE REDES DE ÁGUA, ESGOTO E DRENAGEM, 13., 2014, Fortaleza. Anais... Fortaleza.

COMPANHIA AMBIENTAL DO ESTADO DE SÃO PAULO (CETESB). (2011) Guia Nacional de Coleta e Preservação de Amostras. 2. ed. São Paulo: CETESB. 327 p.

HELMREICH, B.; HILLIGES, R.; SCHRIEWER, A.; HORN, H. (2O1O) Runoff pollutants of a highly trafficked urban road - Correlation analysis and seasonal influences. Chemosphere, v. 80, n. 9. p. 991 997. https://doi.org/10.1016/j.chemosphere.2010.05.037

RAY, S.; KHILLARE, P.S.; AGARWAL, T.; SHRIDHAR, V. (2008) Assessment of PAHs in soil around the International Airport in Delhi, India. Journal of Hazardous Material, v. 156, n. 1-3, p. 9-16. http:// dx.doi.org/10.1016/j.jhazmat.2007.11.099

SHELL. (2013) Manual Safety Data Sheet. Aeroshell Turbine Oil 560 MSDS 857485E. v. 5.1. Disponível em: <http://www.equivashellmsds. com/>. Acesso em: 16 out. 2013.

SPIGLIATTI, S. (2012) Vazamento de óleo na pista fecha aeroporto de Vitória. Estadão, São Paulo, 23 jan. 2012. Disponível em: <http:// www.estadao.com.br/noticias/geral, vazamento-de-oleo-na-pistafecha-aeroporto-de-vitoria,826190,0.htm>. Acesso em: 24 out. 2013.

SULEJ, A.M.; POLKOWSKA, Z.; NAMIESNIK, J. (2011) Contamination of runoff water at Gdansk Airport (Poland) by Polycyclic Aromatic Hydrocarbons (PAHs) and Polychlorinated Biphenyls (PCBs). Sensors (Basel),v.11, n.12,p.11901-11920. https://dx.doi.org/10.3390\%2Fs111211901

SULEJ, A.M.; POLKOWSKA, Z.; NAMIESNIK, J. C. (2O12) Contaminants in airport runoff water in the vicinities of two international airports in Poland. Polish Journal of Environmental Studies, v. 21, n. 3, p. 725-739.

WATTS, R.J. (1997) Hazardous wastes: sources, pathways, receptors. Nova York: John Wiley \& Sons. 764 p.

ZHU, Y.; FANNING, E.; YU, R.C.; ZHANG, Q.; FROINES, J.R. (2011) Aircraft emissions and local air quality impacts from takeoff activities at a large International Airport. Atmospheric Environment, v. 45, n. 36, p. 6526-6533. http://dx.doi.org/10.1016/j.atmosenv.2011.08.062 